\title{
How Significant is the Wave Run-Up Reduction due to Underlayer Permeability in the Design of Rubble-Mound Breakwaters?
}

\author{
D. M. R. Sampath and J. J. Wijetunge
}

Abstract: The present paper.is concerned with an experimental investigation designed to quantify the influence of the permeability of underlayers (filter and core) on the wave run-up over rubble-mound slopes. The run-up measurements were carried out in a laboratory wave channel over a practically useful range of the surf similarity parameter over different structure configurations representing a range of the notional permeability factor $(P)$. The results appear to suggest that the run-up reduction due to underlayer permeability is little, $2 \%$ and $5 \%$, respectively, for values of $P=0.1$ and 0.4 ; however, the runup reduction for structures with $P=0.5$ and 0.6 is not insignificant, viz., $10 \%$ and $15 \%$, respectively.

Keywords : Wave Run-up, Notional Permeability Factor, Permeability, Surf Similarity Parameter, RubbleMound Breakwaters.

\section{Introduction}

Interaction of waves with coastal structures such as breakwaters, seawalls, revetments and dikes causes waves to rush over the slope of the structure. The maximum vertical height reached relative to the still water level when wave action causes a tongue of water to run over the slope of a structure is termed the wave run-up. The runup is the primary parameter required in the design of the crest level of wave damping structures for no or little wave overtopping. The incident wave parameters, the structure slope, the water depth at the toe of the structure, the foreshore slope angle, the surface roughness, the structure geometry and the permeability are the main parameters that influence the wave run-up over a slope.

Many experimental studies have been carried out to characterize the influence of the combined effect of the wave steepness and the structure slope known as the surf similarity parameter on the wave run-up. Further, Wijetunge and Sarma [8] have studied the effect of the surface roughness of the structure slope on the wave runup. More recently, Peiris and Wijetunge [4] examined the effect of the foreshore slope and the relative water depth on the wave run-up on impermeable slopes.

However, comparatively little attention has been paid to investigate the effect of the structure permeability on the wave run-up despite the fact that most of the rubble-mound coastal structures are permeable with one or more underlayers. Even though Shankar and Jayaratne [5] examined the effect of the permeability on the wave runup, they.were not able to differentiate the effect of permeability from that of the surface roughness. Also, Shankar and Jayaratne have used a steel mesh to retain the stones on the slope, so the surface of the slope did not resemble that of a typical rubble-mound. Moreover, their study was limited to a narrow range of the surf similarity parameter. The study of Van der Meer [7] over rock slopes also does not cover the full range of permeable structures encountered in practice; moreover, the considerable scatter present in their data does not allow delineation of the effect of structure permeability.

Consequently, the primary objective of the present study is to quantify the effect of the permeability of the underlayers of rubble-mound coastal structures on the wave run-up over a practically useful range of the surf similarity parameter. It must be added that the present study employs the notional permeability factor as defined by Van der Meer [6] to characterize the permeability of the filter layer/s and core of the structure (see Section $\mathbf{2}$ for further details.).

Eng. D.M.R. Sanprah, AMIE(SL), BSr. Eng (Hons)(Peradenibn), MSeEng (Peradenlya), Lecturer (temp.), Department of Clvil Engineering. University of Peradeniya.

Eng. (Dr) J.J. Wijerunge, AMIE(SL), BSc Eng (Hons) (Morntuwa), PhD (Cambridge), Senior Lecturer. Department of Civll Engineering. Untversily of Peradenlya. 


\section{Experimental Arrangement}

The present experiments were carried out in a wave flume consisting of a regular wave generator and a Perspex walled channel of length $12.75 \mathrm{~m}$, width $0.52 \mathrm{~m}$ and depth $0.70 \mathrm{~m}$ (see Figure 1.) in the Fluids Laboratory of the University of Peradeniya. At the outset, a wooden model of a sloping structure together with a Perspex sheet placed on the face of the slope was installed at the far end of the channel to examine the wave run-up on a smooth surface. The measurements on a smooth surface were utilized to examine the reliability of the experimental setup. Subsequently, a separate Perspex box (see Figure 2) was used to construct the rubble-mound models with different notional permeability factors. This was with the same slope as in the smooth slope and placed at the same location. Stones with different median diameters were used to construct models with different notional permeability factor, which depends on the particle size of the underlayer/s, as shown in Figure 3. A steel wire mesh was fixed to the backside of the Perspex box to retain the material whilst allowing for wave motion.

The wave parameters were recorded using a single, resistant type wave probe (Armfield H40). The use of a single probe meant that the wave parameters could not be obtained at the toe of the structure as the incident waves at a location so close to the structure get distorted by the waves reflected from the structure in no time. In such situations, a two- or three-probe system could be employed to separate incident and reflected waves. However, as such a system was not available, the wave probe was positioned some distance away from the structure so that target wave was not disturbed with the reflected wave due to the structure. Accordingly, after several trial runs over a range of wave periods, the wave probe was placed at a location $4 \mathrm{~m}$ in front of the toe of the structure. The wave records at this location indicated that the reflected waves reach there only after about $5-7$ incident waves have passed the probe. Accordingly, the wave parameters and the corresponding run-up were always recorded for an incident wave that had not been affected by the reflections from the structure (i.e., usually for the $5^{\text {th }}$ or $6^{\text {th }}$ wave). The wave parameters obtained in this manner may be considered as 'deep water' conditions.
A video camera which captures 25 frames per second was employed to obtain the wave run-up on the slope. The video clips obtained in this way were played on a Personal Computer (PC) to obtain the maximum up-rush and then averaged at $5 \mathrm{~cm}$ intervals across the slope laterally to get the run-up. For a particular wave setting, the measurements were repeated five times and the average was taken.

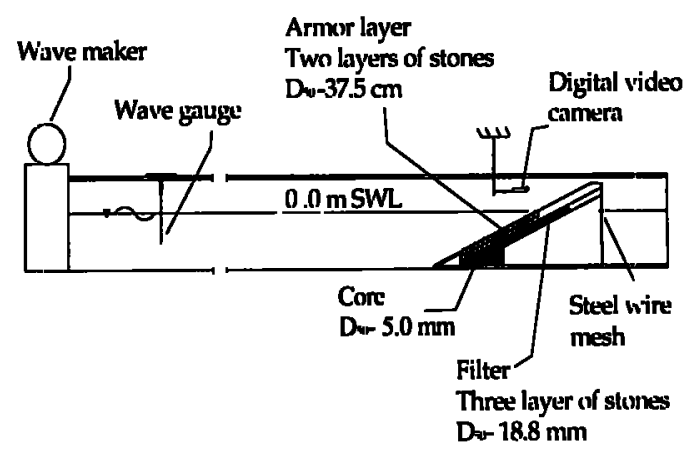

Figure 1 : Experimental Set-Up.

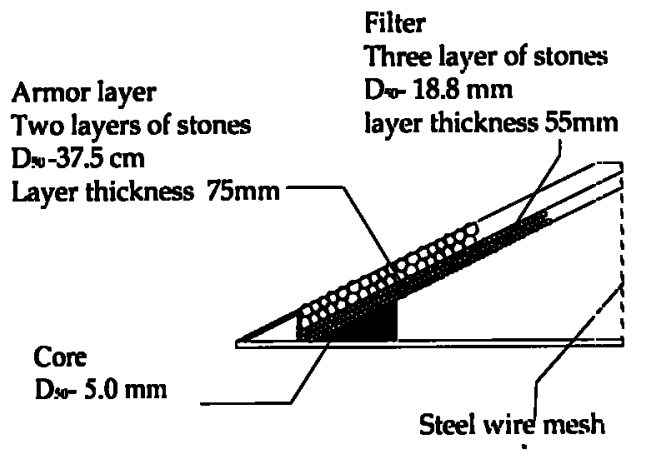

Figure 2 : Cross-Sectional View of the Model.
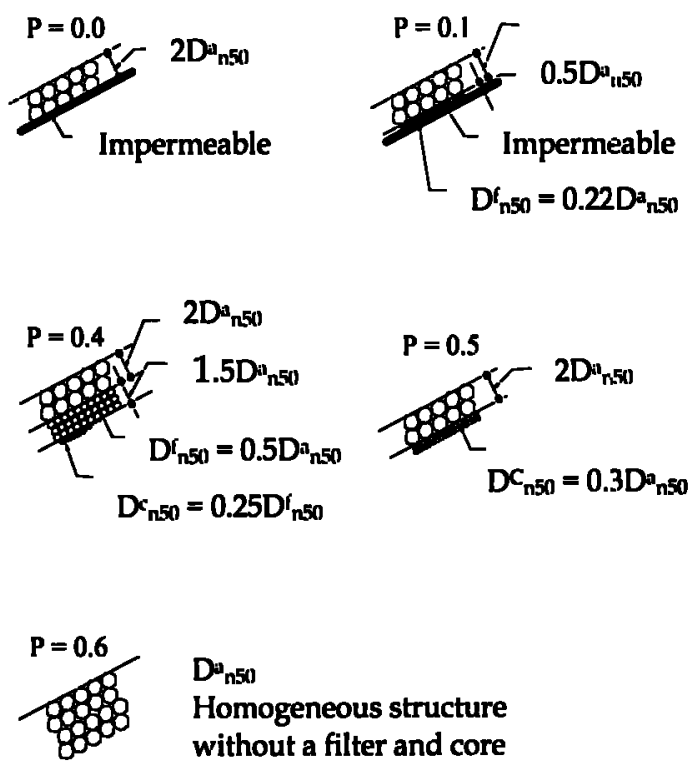

$\mathrm{Du}_{\mathrm{n} 5 \mathrm{O}}$

Homogeneous structure without a filter and core

Figure 3 : Model Structures Tested with Different Notional Permeability $(P=0$ - 0.6). 


\section{Dimensional Analysis}

Dimensional analysis is a useful tool in interpreting the results of an experimental study. The wave run-up ( $R$ ) over a sloping structure depends on the incident wave height $\left(\mathrm{H}_{0}\right)$, the wave period (T), the structure slope $(\alpha)$, the surface roughness $\left(k_{1}\right)$, the permeabiliity $(P)$, the water depth at the toe of the structure $\left(d_{2}\right)$, the fore shore slope $(\beta)$, and the gravitational acceleration (g). Thus, the relative run-up can be expressed as a function of the following nondimensional groups.

$$
\frac{\mathrm{R}}{\mathrm{H}_{0}}=\phi\left[\frac{g T^{2}}{H_{0}}, \frac{d_{1}}{H_{0}}, \frac{k_{1}}{d,}, \tan \alpha, \tan \beta, \mathrm{P}\right]
$$

The foreshore slope angle for the present investigation is kept at zero Moreover, the surface roughness as well as the water depth at the toe of the structure is maintained constant for all test runs by using the same stones with median diameter $\left(D_{50}\right)$ equals to $37.5 \mathrm{~mm}$ for the armour layer. Thus the above expression may be reduced to:

$$
\frac{\mathrm{R}}{\mathrm{H}_{0}}=\phi\left[\frac{g I^{2}}{H_{0}}, \frac{d}{H_{0}}, \tan \alpha, \mathrm{P}\right]
$$

The combined effect of the non-dimensional parameters of structure slope and wave steepness is usually represented by the surf similarity parameter $\left(\zeta_{0}\right)$ defined as:

$$
\zeta_{0}=\frac{\tan \alpha}{\sqrt{s_{0}}}, \text { where, } s_{0}=\frac{2 \pi H_{0}}{g T^{2}} \text {. }
$$

\section{Test Conditions}

The test ranges of the main parameters relevant to the present study are summarized in Table 1. There are two sets of data: the measurements in Data Set $A$ were made over a smooth impermeable slope whilst those in Data Set $B$ are for both rough permeable and impermeable slopes covering a range of the notional permeability, $P=0,0.1,0.4,0.5$ and 0.6 .

The specifications of the rubble-mound models employed to cover a range of the notional permeability tested in the present study are given in Table 2. Note that D85/D15 in Table 2 gives the gradings of stones that were obtained from the respective particle-size distribution curves.
It must be added that, in the construction of armor layer of each structure, the same rubble units were used to ensure the same surface roughness for all tests as far as possible.

Table 1 :

Test Conditions.

\begin{tabular}{|l|l|l|}
\hline \multirow{2}{*}{ Parameter } & \multicolumn{2}{|c|}{ Study Ranges } \\
\cline { 2 - 3 } & $\begin{array}{c}\text { Data Set } A \\
\text { Smooth Slope }\end{array}$ & $\begin{array}{c}\text { Data Set B } \\
\text { Rough Slopes }\end{array}$ \\
\hline$H_{0}$ & $3.75-12 \mathrm{~cm}$ & $3.75-12 \mathrm{~cm}$ \\
$T$ & $0.77-1.00 \mathrm{~s}$ & $0.77-1.00 \mathrm{~s}$ \\
$d_{s}$ & $34.2 \mathrm{~cm}$ & $34.2 \mathrm{~cm}$ \\
$\beta$ & $0 \mathrm{deg}$ & $0 \mathrm{deg}$ \\
$\alpha$ & $24.8 \mathrm{deg}$ & $24.8 \mathrm{deg}$ \\
$d_{s} / H_{0}$ & $2.85-10.00$ & $2.85-10.00$ \\
$\zeta_{0}$ & $1.30-3.00$ & $1.30-3.00$ \\
$P$ & Smooth & $0.0-0.6$ \\
\hline
\end{tabular}

Table 2:

Specifications of Rubble-Mound Models.

\begin{tabular}{|c|l|c|c|c|}
\hline $\begin{array}{c}\text { Notional } \\
\text { Permeability } \\
P\end{array}$ & $\begin{array}{l}\text { Type of } \\
\text { layer }\end{array}$ & $\begin{array}{c}D_{\mathrm{s0}} \\
(\mathrm{mm})\end{array}$ & $\frac{D_{\mathrm{85}}}{D_{15}}$ & $\begin{array}{c}\text { Layer } \\
\text { Thickness } \\
(\mathrm{mm})\end{array}$ \\
\hline $\begin{array}{c}0 \\
\text { Impermeable }\end{array}$ & Armor & 37.5 & 1.25 & 75 \\
\hline $\begin{array}{c}0.1 \\
\text { Impermeable }\end{array}$ & Armor & 37.5 & 1.25 & 75 \\
\hline $\begin{array}{c}0.4 \\
\text { Permeable }\end{array}$ & Armor & 37.5 & 1.25 & 75 \\
\cline { 2 - 5 } & Filter & 18.8 & - & 55 \\
\cline { 2 - 5 } & Core & 5.0 & - & - \\
\hline $\begin{array}{c}0.5 \\
\text { Permeable }\end{array}$ & Armor & 37.5 & 1.25 & 75 \\
\cline { 2 - 5 } & Core & 12.5 & - & - \\
\hline 0.6 & Homoge- & & - & \\
Permeable & neous & 37.5 & 1.25 & - \\
\hline
\end{tabular}

\section{Results and Discussion}

Figure 4 shows the variation of the relative wave run-up with the surf similarity parameter over a smooth impermeable slope for which the inclination angle is $24.8 \mathrm{deg}$. to the horizontal. Figure 4 also shows the measurements of Ahrens [1], Peiris and Wijetunge [4], Wijetunge and Sarma [8] and Van der Meer [7] for comparison. It must be added that the data points of Van der Meer [7] have been derived from run-up measurements with $2 \%$ exceedence and a wave height distribution close to the Rayleigh distribution. 


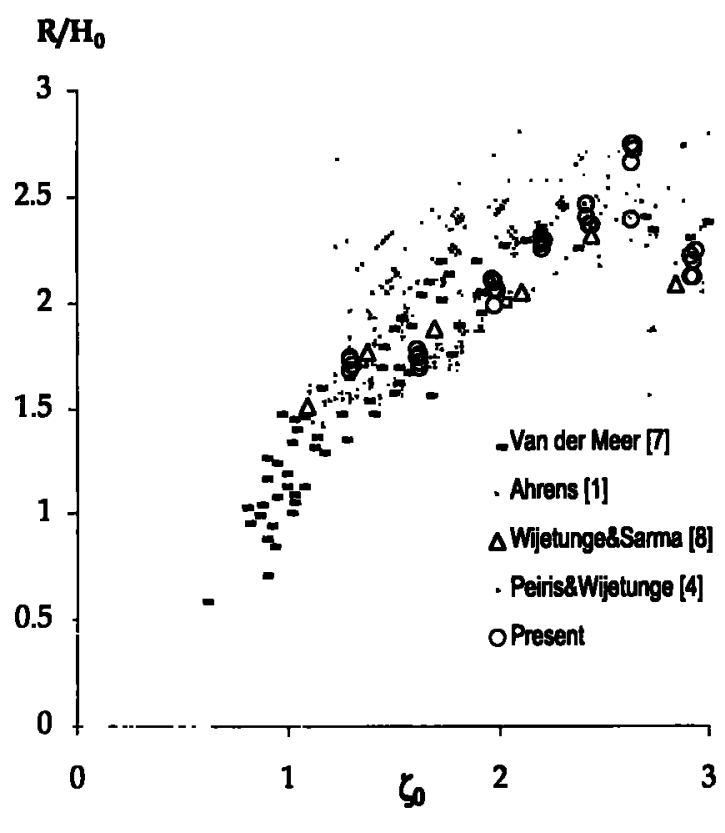

Figure 4 : Variation of Relative Wave Run-Up with Surf Similarity Parameter for Smooth Impermeable Slope.

We see in Figure 4 that the relative wave run-up increases with $\zeta_{0}$ and reaches a peak value at $\zeta_{0} \approx 2.6$ before appearing to decline with further increase of $\zeta_{0}$. Clearly, the present results show good agreement with the measurements of Van der Meer [7] for $\zeta_{0}=1.3-2.4$; thereafter, the present results appear to deviate slightly from the measurements of Van der Meer for $\zeta_{0}=2.6$ and 2.9. However, a similar comparison of the present results with those of Ahrens [1], which exhibit large scatter, shows that the present results fall within the upper and lower bounds of the scatter of his data points. The present measurements also show good agreement with those of Peiris \& Wijetunge [4] and Wijetunge \& Sarma [8]. Accordingly, it may be concluded that the present measurements agree well with the previous results thus verifying the reliability of the present experimental arrangement as well as the procedure.

Figure 5 gives the variation of $R / H_{0}$ with $\zeta_{0}$ for rough slopes with different notional permeability, i.e., $P=0.0,0.1,0.4,0.5$ and 0.6 .

The results presented in Figure 5 for a range of $P$ could be used to quantify the effect of underlayer permeability, as the present measurements enable us to differentiate the effect of permeability from that of the surface roughness. We see that the relative wave run- up decreases when the notional permeability is increased. This probably is not surprising because permeable structures allow part of the water running up the slope to sink into it thus leading to lesser run-up heights.

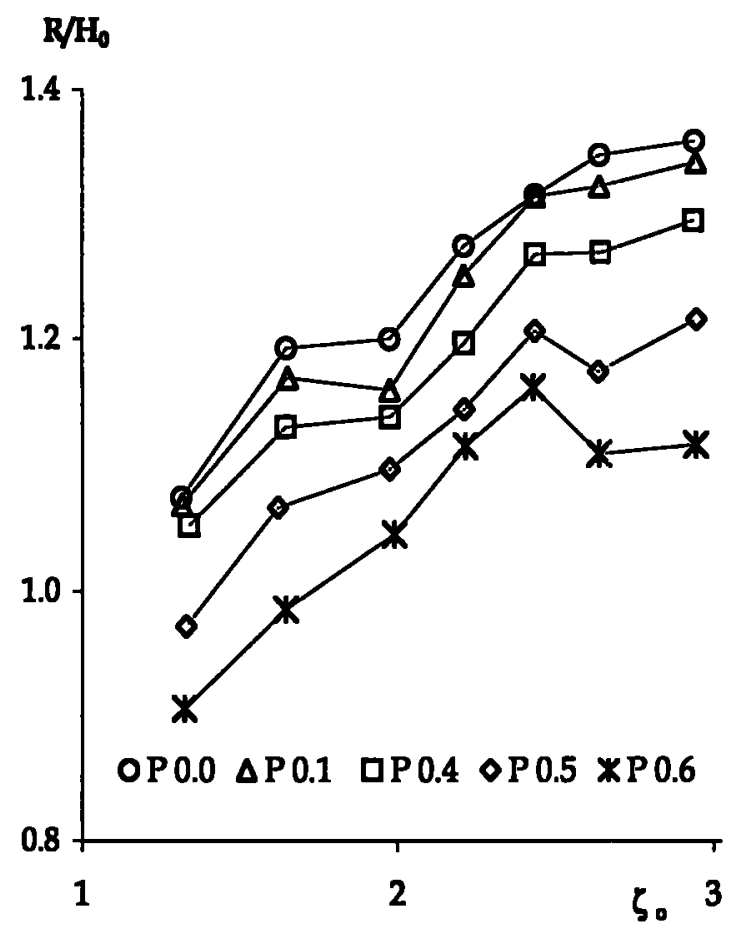

Figure 5 : Variation of Relative Wave Run-Up with Surf Similarity Parameter for Rough Slopes of Different Notional Permeability.

This increase of wave run-up in comparatively less permeable structures can be further explained using the recorded traces of the phreatic surface and the internal set-up through the structure. The visual observations of the flow through the permeable structures revealed that, when the porosity and permeability of the under layers of the rubble-mound are decreased an internal setup of the water table is built up with the wave action. This means that, while the wave runs down the slope, the internal water table remains at a certain elevated level with respect to the mean water line without waves. This may be due to the slow rate of drawdown of water out of the structure when permeability is low. It must be noted that, the rise of the phreatic surface due to the internal set-up could impede the free movement of water inside the porous-structure thus offering a resistance to the transmission of water through the structure. Consequently, there could be more water available to run over the surface of the structure leading to an increase in the relative run-up.

Figure 6 illustrates the observed variations of the internal set-up and the phreatic surface in the permeable structures with respect to the position of the wave running up/down the slope. Figure 
$6(a)$ and $(b)$ show the water surface elevation for a structure with $P=0.6$, and $\alpha=24.8^{\circ}$. The internal set-up shown in Figure $6(a)$ for $\zeta_{0}=1.28$ is about 3 to $4 \mathrm{~mm}$ whereas that in Figure $6(\mathrm{~b})$ for $\zeta_{0}=2.50$ shows no significant set-up.

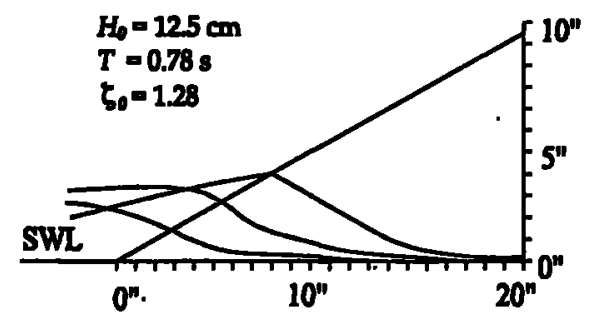

(a)

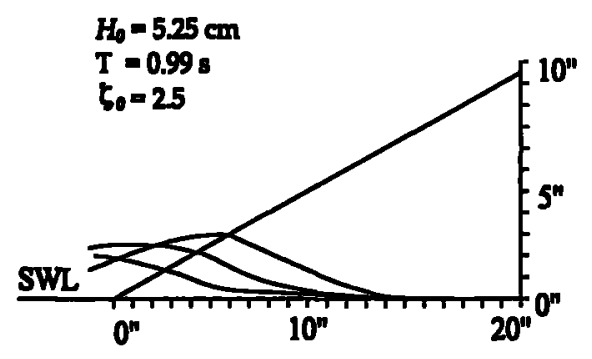

(b)

Figure 6 : Recorded Traces of Internal Set-Up in the Permeable Structures with Respect to the

Position of Wave, for $\alpha=24.8^{\circ}$ and $P=0.6$.

It can be seen that the internal set-up depends on the wave height $\left(H_{0}\right)$ too. When a large wave interacts with the structure internal pores at higher levels could get filled with water and this may also help increase the internal set-up.

It also appears that, the relative wave run-up increases with $\zeta_{0}$ for $\zeta_{0}=1.3$ to 2.4; however, from $\zeta_{0}=2.4$ to $3.0, R / H_{0}$ remains nearly constant for permeable structures, i.e., for $P=0.4,0.5$ and 0.6 . This appears to suggest that, for surging wave conditions, permeable rubble-mound structures show no variation in relative wave run-up with $\zeta_{0}$. Nevertheless, further investigations are necessary to firmly establish the behaviour of wave run-up over permeable slopes under surging waves for values of $\zeta_{0}$ beyond 3.0.

We now compare the present measurements with those of Van der Meer [7] for rough impermeable $(P=0.1)$ and rough permeable $(P=0.5)$ slopes. Despite the considerable scatter present in van der Meer's data, we see that the present results, on the whole, fall within van der Meer's data points.

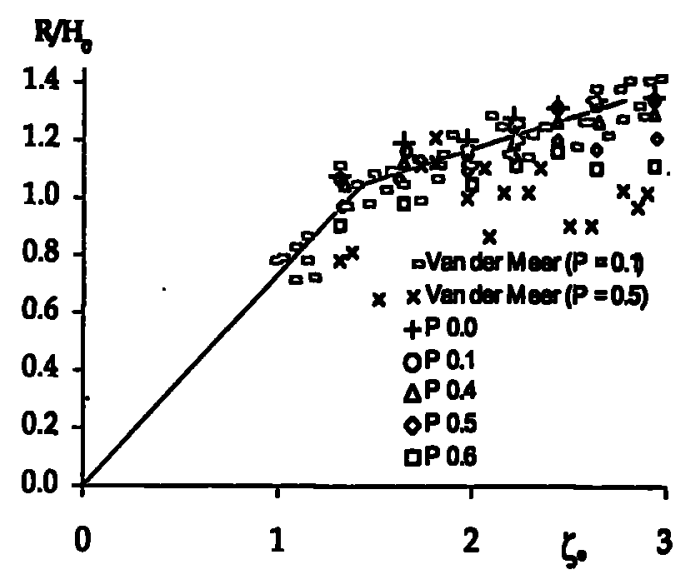

Figure 7 : Comparison of Present Measurements with those of Van der Meer (1992).

Now, we define a run-up reduction factor for the effect of underlayer permeability of rubblemound breakwaters:

$\gamma_{P}=\left[\frac{\left(R / H_{0}\right)_{P}}{\left(R / H_{0}\right)_{P=0}}\right.$,

i.e., as the ratio between the relative run-up over a given breakwater with permeable underlayer/ $s$ and that without an underlayer (two layers of armour stones placed on an impermeable surface for which laboratory experimental results are often available.).

Figure 8 shows the way in which the values of $\gamma_{p}$ vary with $\zeta_{0}$ for all values of notional permeability investigated. We see that the run-up reduction factor $\gamma_{p}$ does not appear to show any consistent trend, so the range of values of $\gamma_{p}$ as well as the mean for each value of $P$ are given in Table 3 .

It appears that the run-up reduction due to underlayer permeability is little, $2 \%$ and $5 \%$, respectively, for values of notional permeability $P=0.1$ and 0.4 . However, the run-up reduction for structures with $P=0.5$ and 0.6 is not insignificant, $10 \%$ and $15 \%$, respectively, and could probably be accounted for in an economical design.

Table 3 :

Reduction Factors $\left(\boldsymbol{y}_{\boldsymbol{p}}\right)$.

\begin{tabular}{|c|c|c|}
\hline $\begin{array}{c}\text { Notional } \\
\text { Permeability } \\
(\mathbf{P})\end{array}$ & $\begin{array}{c}\text { Range of } \\
\gamma_{\mathbf{p}}\end{array}$ & $\begin{array}{c}\text { Mean Value of } \\
\gamma_{\mathbf{p}}\end{array}$ \\
\hline 0.1 & $0.97-0.99$ & 0.98 \\
0.4 & $0.94-0.96$ & 0.95 \\
0.5 & $0.89-0.92$ & 0.90 \\
0.6 & $0.82-0.88$ & 0.85 \\
\hline
\end{tabular}




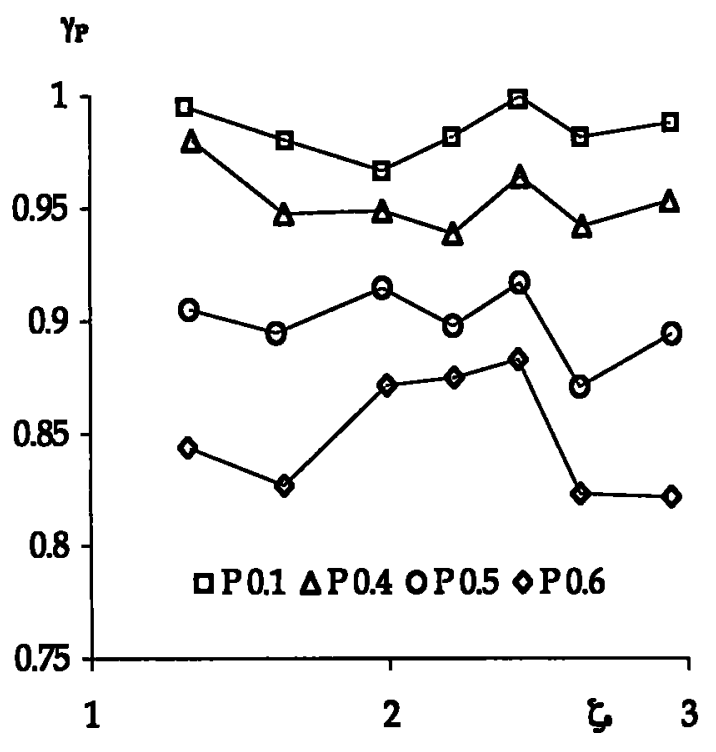

Figure 8 : Variation of $\boldsymbol{\gamma}_{\mathbf{p}}$ with Surf Similarity Parameter for Different Notional Permeability.

\section{Conclusions}

Detailed measurements have been carried out to quantify the influence of the underlayer permeability on the wave run-up over rubblemound slopes. The following conclusions are drawn for the range of conditions covered in the present investigation.

Although the relative wave run-up $\left(R / H_{0}\right)$ steadily increases with $\zeta_{0}$ for $\zeta_{0}=1.3$ to 2.4 for all values of notional permeability $(P)$ tested, $R / H_{0}$ remains nearly constant for $\zeta_{0}=2.4$ to 3.0 over permeable structures, i.e., for $\mathrm{P}=0.4,0.5$ and 0.6 .

The results appear to suggest that the run-up reduction due to underlayer permeability is little, $2 \%$ and $5 \%$, respectively, for values of notional permeability $P=0.1$ and 0.4 . However, the runup reduction for structures with $P=0.5$ and 0.6 is not insignificant, $10 \%$ and $15 \%$, respectively.

\section{Acknowledgment}

The first author gratefully acknowledges the financial support from the Science \& Technology Personnel Development Project of the Ministry of Science \& Technology, Sri Lanka, which enabled him to carry out the experimental work described in the present paper.

\section{References}

1. Ahrens, J.P. "Irregular wave run-up on smooth slopes", Tech. Aid No. 81-17, Coastal Engineering Research Centre, Waterways Experiment Station, Vicksburg, Miss., 1981.

2. Constal Engincering Mnunal, Coastal Engineering Research Centre, U.S. Army, The U.S. Government Printing Office, Washington D.C., 2002.

3. De Waal, J.P. and Van der Meer, J.W. "Wave runup and overtopping on coastal Structures" Proceeding of the $23^{n}$ Int. Conf. on Coastal Engrg, Vol, 2, pp. 1758 - 1771, 1992.

4. Peiris, D.A. and Wijetunge, J. J. "Effect of foreshore slope angle on wave run-up on sloping structures". Annual Transactions of the Institution of Engineers, Sri Lanka, Volume 1 - Part B, 2004, pp. 305 - 312.

5. Shankar N.J. and Jayaratne, M.P.R. “Wave run-up and overtopping on smooth slopes of coastal structures", Ocean Engineering 30, 221-238, 2002.

6. Van der Meer, J.W. "Conceptual design of rubble mound breakwaters", pp. 221-315, in Philip L.-F. Liu, Advances in Constal and Ocenn Engincering, Vol. 1, World Scientific, Singapore, 1996.

7. Van der Meer, J.W. and Stam, J. "Wave run-up on smooth and rock slopes of coastal structures", ASCE J Waterway, Port, Coastal and Ocean Engineering. Vol 118, 534-550, 1992.

8. Wijetunge, J. J. and Sarma, A. K. “Effectiveness of $2 D$ strip elements in wave run-up reduction over smooth slopes". Engineer, Journal of the Institution of Engineers, Sri Lanka, Vol. XXXVI, No. 3, Section-I, pp. 39-46, 2003. 